\title{
Continuous ECG Recording for Non- human Species Using Implanted Leads
}

National Cancer Institute

\section{Source}

National Cancer Institute. Continuous ECG Recording for Non-human Species Using

Implanted Leads. NCI Thesaurus. Code C154718.

A continuous electrocardiographic (ECG) recording utilizing one or more implanted leads in a non-human species. (CDISC) 